\title{
Genetic counselling: A tool for the prevention of some abnormal pregnancies
}

\author{
MARTIN BOBROW \\ From the Department of Medical Genetics, Oxford Area Health Authority $(T)$
}

A pregnancy contains a fetus, and if the fetus is abnormal the pregnancy is in one sense also abnormal. In this context, a consideration of genetic counselling is apposite to the pathology of pregnancy. Although counselling is not in itself a pathologist's technique, it is becoming increasingly reliant on sophisticated laboratory services, and genetic counsellors are often members of laboratory-based teams.

Genetic counselling has been defined as 'a communication process which deals with the human problems associated with the occurrence, or risk of recurrence, of a genetic disorder in a family . . .' (American Society of Human Genetics, 1975). The accent is on communication, leading to an appreciation by the patient or his family of the nature and prognosis of the disorder, and the likelihood that it will recur in the family. Counselling is only one aspect of the newly emerged discipline of medical genetics, a subspeciality dealing with diagnosis, laboratory investigation, prognostication and treatment of genetically determined disorders. This paper will briefly review the subject of genetic counselling, considering (a) the types of medical conditions for which referral to a medical geneticist is appropriate, (b) the size of the population suffering from genetically determined disorders, (c) the techniques, and (d) the efficacy of genetic counselling.

\section{The Scope of Medical Genetics}

The genetically determined disorders of man may be divided for convenience into (1) those due to the effects of a single major gene, (2) those in which a chromosomal abnormality can be detected at a microscopic level, and (3) conditions thought to be due to the interaction of several genetic and environmental factors. Such 'multifactorial' inheritance has as its hallmark a familial aggregation of the disorder, but with lower recurrence risks than occur with simply inherited traits (Carter, 1969). This group includes many of the common congenital malformations, as well as some conditions of later onset such as diabetes.

Over two thousand conditions of known inheritance are now described (McKusick, 1975) and the diagnosis or suspicion of such a condition may prompt referral to a geneticist.

Because many malformation syndromes are of genetic origin, the medical geneticist has tended to become a 'syndromologist' and undiagnosed cases of congenital malformations, mental retardation, inter-sexuality, and infertility, etc, are often referred in the hope (sadly, often forlorn) that a definitive diagnosis will be forthcoming.

Probably reasonably representative of the patterns of referrals to genetic clinics are series published from Oxford (Stevenson and Davison, 1966) and Yale (Hsia, 1974). Chromosome abnormalities account for $19 \%$ and $26 \%$ of referrals to the two clinics; single gene traits for 26 and $31 \%$ respectively, while the remainder include congenital malformations and diseases of multifactorial origin, those of unknown aetiology, and a few miscellaneous requests relating to consanguineous marriages or adoptions.

\section{The Frequency of Genetically Determined Disorders}

Semantic problems surround exactly what constitutes a 'genetic disorder'. Particularly amongst multifactorial traits, the line can be drawn very widely indeed. Even allowing for this, it can be readily shown that genetically influenced disorders account for quite a substantial amount of morbidity in human populations. Roberts et al (1970) estimated that they accounted for $42 \%$ of paediatric mortality. Clow et al (1973) analysed a random sample of 1145 admissions to a Canadian children's hospital in $1969 / 70 ; 6 \cdot 78 \%$ were related to single gene traits, $3.9 \%$ to multifactorial conditions, $0.4 \%$ to chromosome anomalies, and a further $18 \%$ to congenital malformations, some of which will have a genetic 
component. A total of $30 \%$ of admissions are, therefore, for conditions within the ambit of interest of the medical geneticist.

The incidence of genetic disease in populations at birth has also been studied. In a recent report from British Columbia (Trimble and Doughty, 1974) single gene traits were present in $2 \cdot 3 / 1000$ births, congenital malformations in $42 \cdot 8 / 1000$, and other multifactorial conditions in $47 \cdot 3 / 1000$. Chromosome anomalies were present in $2 / 1000$ births, but this excluded all sex chromosome anomalies, which would increase the figure nearly three-fold. The authors conclude that 'about $\mathbf{9 . 4}$ individuals out of every 100 liveborn will have serious genetic diseases or handicaps', although the seriousness of these conditions varies quite widely.

\section{The Techniques of Genetic Counselling}

These can be considered in two parts: the methods for estimating a recurrence risk, and the problems of conveying this information to the family members concerned.

\section{ESTIMATION OF GENETIC RISKS}

Genetic risks may be estimated in two ways: on theoretical grounds, where the condition is inherited according to Mendelian principles, and empirically, on the basis of published data, when it is not so inherited. Empirically derived recurrence risks, applicable to many multifactorially determined conditions, are available in standard texts (Nora and Fraser, 1974). The risk of recurrence is generally in the $1 \%$ to $5 \%$ range after one affected child, and increases if there is more than one affected person in the pedigree. More complex pedigrees can be assessed with published tables or computer programmes (Bonaiti-Pellie and Smith, 1974), although careful measurement of relatively small risks is of questionable clinical relevance.

Risk figures for persons known or thought to be carrying single gene mutations are usually relatively easily calculated on Mendelian principles. The calculations can become somewhat more complex when trying to assess the probability that an individual will inherit a particular gene through several generations, making maximum use of the information provided by unaffected members of the pedigree. Such situations only arise with any frequency in X-linked conditions, and methods of dealing with them are available (Murphy, 1970; Maag and Gold, 1975). Laboratory information relevant to carrier status, such as creatine phosphokinase levels in Duchenne muscular dystrophy, can also be incorporated into these estimates.
Recurrence risks for chromosome anomalies are generally empirically based. The theoretical behaviour of chromosomal translocations is well known, but actual recurrence risks appear to be lower than these predictions, possibly because of the loss of some chromosomally unbalanced zygotes in early pregnancy.

No genetic risk can be satisfactorily estimated unless an accurate diagnosis is made. There are many examples of fairly similar clinical conditions with widely disparate modes of inheritance, and the genetic counsellor must be constantly aware of this problem.

\section{THE TECHNIQUES OF COMMUNICATING} GENETIC INFORMATION

The results of genetic investigation are usually conveyed to the patients during one or more interviews. The variation in individual circumstances makes it impossible to lay down rigid precepts for this process, but there is reasonable consensus amongst genetic counsellors on some basic principles.

The most common counselling situation, by far, involves a couple who have had one abnormal child, and are concerned about subsequent pregnancies. The views and attitudes of the two parents may not coincide, and it is obvious that any decision reached must be agreed by both parties if a substantial hazard of intramarital friction is not to arise. Both parents, or all interested parties, should therefore be present at counselling sessions.

The emphasis is on conveying information, not on dictating a course of action. The final decision as to how to use the information must rest with the persons being counselled, who will bear the brunt of any consequences of this decision. The extent to which positive guidance towards a particular decision is given varies greatly amongst counsellors. I, personally, remain neutral until I detect an emerging decision from the parents. If this decision seems reasonable, I reinforce it; if not, I try to probe the motives behind reaching the unusual decision. If asked directly for an opinion as to the most reasonable course of action, I give it bluntly, but point out that this would be my decision, to suit my own circumstances, and need not necessarily be the best decision for any other person.

It is clear from this that, although there is no attempt at persuasion, my attitude is not really neutral in the sense that $I$ have no preference for one course of action over the other. It is, however, virtually impossible to present information in a totally neutral way: 'a $1 / 10$ risk of abnormality' does not sound the same as 'a 10:1 probability of a normal child'. This is not a problem which can be solved, it is simply something to be aware of, so that 
a choice of words can be made consciously rather than randomly.

The valuable concept of genetic 'burden' as opposed to 'risk' (Leonard et al, 1972) suggests that the disadvantages of having another affected child are measured by a complex factor, which includes the probability that the event will occur, the severity of the disorder if it does occur, and its duration (in crude terms, the probable survival of an affected child). Also relevant are the home circumstances into which the child would be born, as well as the personalities of the parents, for these will ultimately determine the magnitude of the 'perceived burden' for the family. Difficult though it may be, it is the probable magnitude of this perceived burden which must be assessed, and conveyed to the parents. The balance between this, and the parental desire for another child, will be the major determinants of their choice of action.

In practical terms, the patients must therefore be clearly and truthfully informed of the likely medical prognosis for affected children, as well as the purely genetic considerations of recurrence risk.

The concept of a decision based on genetic counselling as essentially a gambling decision has been well explored by Pearn (1973). The concept of probabilities is often difficult to grasp, and the discussion must be assisted by means of analogies, and by restatements of the risks in several different ways. Even for highly educated people, this aspect of counselling should be kept as simple as possible. In complex situations, such as where the counsellor is not completely confident of the diagnosis (profound childhood deafness is a good example, where recessively inherited and non-genetic cases cannot be clinically distinguished, and the estimated risk must take this doubt into account), there is a strong temptation for the counsellor to offload onto his patients the emotional trauma of compounding so many uncertainties into a risk figure, by explaining in minute detail how the final figure is derived. I have a suspicion that those long lines of multiplicative probabilities are far from helpful to patients already in a somewhat depressed state: they want a final figure, perhaps with some general idea of the counsellor's confidence in its accuracy, and wish to be spared the agonising detail as far as possible.

The bare facts need to be put into some perspective for the patients. Particularly relevant are such data as the population incidence of the disorder in question, and the overall frequency of abnormal births (which represents the basic risk run by any couple having a child). A brief discussion of the biology of the disorder may be helpful; most people feel better able to face a simple chemical or mechanical error than a nameless monstrous spectre of disordered development.

An element of guilt is almost bound to be present in the parents of an abnormal child. This should be positively attacked, by discussing the relevance (or, more commonly, irrelevance), of dietary factors, teratogens, falling down stairs, alcoholic grandparents, and other shady shibboleths. All normal people carry one or more deleterious or lethal recessive gene, and it is (apart from consanguineous marriages) pure bad luck to acquire a spouse who carries the same mutant. Discussions of such problems as the influence of maternal age on chromosome nondisjunction are often highly relevant, but must be sensitively dealt with in order not to allow one marital partner to blame the other for the family disaster. People who are models of reason and restraint in a clinic can, I am assured, behave quite differently during the throes of a domestic dispute.

Having acquired the relevant information, the parents will eventually be required to make some sort of decision about their future. The options which face them are stark: (1) take the risk (modified where relevant, by the possibility of antenatal diagnosis and selective abortion, a vitally important subject not dealt with at length in this paper, as it will come into the subsequent papers of this symposium); (2) abstain from further reproduction, involving contraception or sterilization; (3) adoption, or (4) have a child of different biological parentage, either by AID, or by divorce and remarriage, or any other means.

Whatever decision is taken, the family may need help in implementing it, and emotional support may be desperately needed during the decision and in the trying periods of waiting through subsequent pregnancies. Although other agencies, medical and non-medical, may be better equipped to deal with those problems than the genetic counsellor, he should at least try to ensure that the patients know where to go for help and advice.

Some counsellors regularly follow up their interviews by sending a written summary of the information to the patient. Patients said they appreciated this (Hsia, 1974), but the subsequent reproductive performance of this group of counselled patients did not differ from those in other reported series, where reinforcing letters were not regularly sent (Carter et al, 1971; Emery et al, 1972, 1973; Leonard et al, 1972). Leonard et al (1972) studied the parents of children with cystic fibrosis, some of whom had read literature distributed by the Cystic Fibrosis Foundation on the biology of the disease. The attitudes and behaviour of this group of parents did not differ from those who had not read the pamphlets. 
THE EFFICACY OF COUNSELLING

There are two broad aims of genetic counselling, and its efficacy must be assessed relative to each of them. First, counselling is intended to give families understanding of the facts and implications relating to their hereditary disorders. This understanding is expected, per se, to alleviate some of the anxiety, guilt and general unpleasantness of their situation. Secondly, it is implicitly hoped that this understanding will modify the reproductive behaviour of the affected families, so that in general the load of genetically determined disease will be diminished. It deserves emphasis that, although the counsellor may not direct individual couples towards particular decisions regarding further pregnancies, he must be concerned that, as a population, high-risk groups ought to be relatively discouraged from further childbearing. Conversely, low-risk populations ought to be relatively encouraged to further reproduction. Unless these effects are discerned, it indicates that the genetic information is not being put to effective use by its recipients.

The first function of conveying information to promote objective insight is normal medical practice. Perhaps because genetic counsellors spend a long time with individual patients, often in family groups, talking about relatively non-technical matters, a good rapport is frequently established. I, and many of my colleagues, have been regularly gratified by patients' enthusiasm for these detailed discussions. Although pleasant and valuable, this work does not necessarily require a specialized geneticist; it requires time and sympathy. Without denigrating this role of the genetic counsellor as physician and psychologist, it would be wrong to assess the value of genetic counselling (as opposed to any form of family counselling) on the basis of patient satisfaction, which is bound to be largely based on this type of consideration.

Several groups have published follow-up data on couples who have experienced genetic counselling (Carter et al, 1971; Leonard et al, 1972; Emery et al, 1972, 1973; Hsia, 1974). Apart from general questions of patient satisfaction with the procedure, they have addressed themselves to $(a)$ patients' comprehension of basic genetic theory, $(b)$ recall of the precise risk figures given, and $(c)$ postcounselling reproductive performance.

Some patients desire information on the basic biology of their medical problem, but others do not. This is found in all branches of medicine. Clearly, those who desire the information should be given it, but I can see no prima facie reason why such understanding should be a prerequisite for making sensible decisions about subsequent pregnancies, nor do I know of any evidence suggesting that this is so. One can also argue that whether patients have accurate recall of the risk figure given them is of little comfort if they fail to modify their reproductive plans accordingly. Conversely, people may forget the exact risk figures, but retain a general impression of the 'mood' of the interview sufficient to enable them to act. It would, therefore, seem that the only reasonable test of the 'genetic' content of genetic counselling sessions is the subsequent reproductive performance of the families concerned.

The table summarizes published information from four different centres, based on follow up of 714 couples referred for genetic counselling. The series which have been summated are not exactly comparable, but there is a reasonable degree of uniformity among them. With a high recurrence risk $(1 / 10$ or greater) about $70 \%$ of couples said they were discouraged from further pregnancies; with a risk of less than $1 / 10,70 \%$ contemplated more children.

\begin{tabular}{lcc}
\hline Intention & \multicolumn{2}{l}{ Genetic Risk } \\
\cline { 2 - 3 } & $>1 / 10$ & $<1 / 10$ \\
\hline No further pregnancies & $225(68 \%)$ & $99(26 \%)$ \\
Plan further pregnancies & $86(26 \%)$ & $265(70 \%)$ \\
Undecided & $22(7 \%)$ & $17(4 \%)$ \\
Total & 333 & 381 \\
Actual number of further pregnancies & & \\
$\quad$ recorded & 132 & 257 \\
Mean pregnancies/couple & 0.49 & 0.83 \\
\hline
\end{tabular}

Table The reproductive intentions of families after genetic counselling 1

'Based on the data of Carter et al (1971); Leonard et al (1972); Emery et al (1972, 1973); Hsia, (1974).

Although this shows a marked difference between groups, it is far from perfect. Furthermore, the actual number of pregnancies recorded shows even less of a difference between the groups (table), probably due to contraceptive failure in the high-risk couples. In the series of Leonard et al (1972) eight of 31 couples who stated that they were deterred from further pregnancies were nevertheless not using any form of contraception; about $20 \%$ of high-risk couples reported by Emery et al (1973) were not using contraception. Genetic counselling should be allied to effective contraceptive advice.

In evaluating the effect of genetic counselling, it is also relevant to ask how many children these couples might have produced in the absence of counselling. I am not aware of any data on this point. Although the internal comparison of high- and lowrisk groups gives one some idea, differences in the clinical presentation of conditions giving rise to high and low risks makes the control an imperfect one. Leonard et al (1972) interviewed a group of parents of children with various connective tissue disorders, 
thought to have a negligibly low recurrence risk. Despite the absence of any genetic counselling, $20 \%$ regarded the disease as a reason for curtailing reproduction, and $50 \%$ were actually employing some form of contraception.

\section{Conclusion}

The sophistication of techniques for providing accurate genetic diagnoses and prognoses is expanding rapidly. This, and in particular the new and very important field of antenatal diagnosis (which has not been dealt with in this paper), have consolidated the role of the medical geneticist within the framework of modern medicine. There is an obvious demand for the service, with most major centres in the UK now having established posts for medical geneticists, and an increasing number of annual referrals to genetic clinics.

Carefully controlled follow-up information on subjects of genetic counselling is still, however, sparse. We are therefore seriously lacking information on the most advantageous and efficient (for counselling time will become increasingly valuable as the referral rate rises) means of communicating genetic information to patients.

\section{References}

American Society of Human Genetics (1975). Report of Ad Hoc Committee on Genetic Counseling. Amer. J. hum. Genet., 27, 240-242.

Bonaiti-Pellié, C., and Smith, C. (1974). Risk tables for genetic counselling in some common congenital malforma- tions. J. med. Genet., 11, 374-377.

Carter, C. O. (1969). Genetics of common disorders. Brit. med. Bull., 25 52-57.

Carter, C. O., Roberts, J. A. F., Evans, K. A., and Buck, A. R. (1971). Genetic clinic: a follow-up. Lancet, 1, 281285.

Clow, C. L., Fraser, F. C., Laberge, C., and Scriver, C. R. (1973). On the application of knowledge to the patient with genetic disease. Progr. med. Genet., 9, 159-213.

Emery, A. E. H., Watt, M. S., and Clack, E. R. (1972). The effects of genetic counselling in Duchenne muscular dystrophy. Clin. Genet., 3, 147-150.

Emery, A. E. H., Watt, M. S., and Clack, E. (1973). Social effects of genetic counselling. Brit. med. J., 1, 724-726.

Hsia, Y. E. (1974). Genetic counselling. In Genetic Responsibility, edited by M. Lipkin and P. T. Rowley, pp. 43-59. Plenum Press, New York.

Leonard, C. O., Chase, G. A., and Childs, B. (1972). Genetic counseling: a consumer's view. New Engl. J. Med., 287, 433-439.

Maag, U. R., and Gold, R. J. M. (1975). A simple combinational method for calculating genetic risks. Clin. Genet., 7, 361-367.

McKusick, V. A. (1975). Mendelian Inheritance in Man, 4th ed. Johns Hopkins University Press, Baltimore and London.

Murphy, E. A. (1970). The Ensu scoring system in genetic counselling. Ann. hum. Genet., 34, 73-78.

Nora, J. J., and Fraser, F. C. (1974). Medical Genetics: Principles and Practice. Lea and Febiger, Philadelphia.

Pearn, J. H. (1973). Patients' subjective interpretation of risks offered in genetic counselling. J. med. Genet., 10, 129134.

Roberts, D. F., Chavez, J., and Court, S. D. M. (1970). The genetic component in child mortality. Arch. Dis. Childh., 45, 33-38.

Stevenson, A. C., and Davison, B. C. C. (1966). Families referred for genetic advice. Brit. med. J., 2, 1060-1062.

Trimble, B. K., and Doughty, J. H. (1974). The amount of herediatry disease in human populations. Ann. hum. Genet., 38, 199-223. 